EESTI NSV TEADUSTE AKADEEMIA TOIMETISED. 20. KÖIDE

KEEMIA * GEOLOOGIA. 1971, NR. 1

ИЗВЕСТИЯ АКАДЕМИИ НАУК ЭСТОНСКОЙ ССР. ТОМ 20 ХИмИЯ * ГЕОЛОГИЯ. 1971, № 1

\title{
ТОКСИЧНОСТЬ ПРОДУКТОВ ДЕГРАДАЦИИ ФЕНОЛОВ В ЗАВИСИМОСТИ ОТ МАКРОМЕХАНИЗМА ПРОЦЕССА ОКИСЛЕНИЯ
}

Токсичность фенолов различной структуры изучена сравнительно широко. Однако эффективность процессов естественной или принудительной деградации фенолов обычно характеризуется не изменением их токсичности, а только химическим потреблением кислорода или снижением концентрации исходного вещества. Сочетание упомянутых показателей с определением токсичнссти продуктов окисления фенолов служило предметом наших предыдущих сообщений $\left[{ }^{1,2}\right]$. Нами показано, что в процессе аутооксидации 5-метилрезорцина (орцина) токсичность продуктов даже несколько возрастает по сравнению с показателем для исходного вещества.

В настоящей работе изучена токсичность реакционных смесей после окислительной деградации фенолов различной структуры.

Результаты ранее проведенных нами опытов [3] позволяют утверждать, что из использованных подопытных животных наиболее чувствительны к токсическому воздействию орцина белые мыши и белые крысы, менее чувствительны - морские свинки и кролики. Исходя из этого, токсичность продуктов разложения (окисления) фенолов изучалась в острых опытах на 331 белой крысе весом 180-250 г. Вещества вводились в желудок однократно в виде водных растворов или мелкодисперсной водной суспензии через металлический зонд в дозе, соответствующей $D L_{50}$ исходного вещества в мг на кг веса животного.

Наблюдения за выживаемостью животных и их состоянием проводились в течение 15 суток после введения изучаемых веществ. Затем животные умерщвлялись путем декапитации и подвергались патогистологическому исследованию.

\section{Результаты исследования и их обсуждение}

Дозы (мг/кг) продуктов окисления фенолов в опыте оказались близкими к $D L_{50}$ исходного фенола. Указанные дозы, как видно из табл. 1-3, вызвали значительно меньшее количество смертельных исходов, чем исходные фенолы.

Острое отравление орцином характеризовалось появлением одышкн и нарушением координации движений, быстрым наступлением клонических судорог, переходящих в клонико-тонические, а в дальнейшем в «боковое» положение, после чего следовала смерть части животных. 
Смерть животных при острой интоксикации орцином наступала в течение 1-6 ч от момента введения орцина, в остальных случаях, как правило, на протяжении первых двух суток [4].

Картина отравления орцином напоминала картину отравления другими фенолами - диметилфенолом, $\alpha$ - и $\beta$-нафтолами, гидрохиноном и др. Картина интоксикации продуктами разложения фенолов была аналогична картине отравления орцином и другими фенолами, однако клинические симптомы отравления в этом случае менее выражены.

Судороги по своему характеру в основном тонические в виде тремора у крыс, получивших продукты разложения фенолов, орцина и оксибензола, были значительно менее выражены и продолжались не более 30-60 мин, после чего животные выздоравливали.

Особенно резкое различие обнаружено при введении фенола (оксибензола) и продуктов его окисления. В последнем случае судороги наступили через 10-15 мин после введения вещества и оказались исключительно слабовыраженными.

В эксперименте с орцином и оксибензолом на 8-е и 15-е сутки после введения фенолов определялся вес выживших подопытных крыс. Установлено, что все подопытные крысы прибавили в весе столько же, сколько и контроль (контролем служили белые крысы того же возраста, не получавшие фенолов). Посмертно во внутренних органах макроскопически никакие отклонения от нормы не обнаружены.

Опыты сгруппированы следующим образом: 1) продукты аутооксидации (молекулярным кислородом) различных фенолов в щелочной среде, 2) продукты инициированного в нейтральной среде окисления орцина и 3) то же для фенола. Методика эксперимента для первой группы и результаты химического и аналитического исследований подробно охарактеризованы ранее [5,6]. При таком способе окисления фенолов основная доля продуктов является полимерными и поликонденсированными соединениями. Часть «полимеров» обладает большим молекулярным весом и нерастворима в воде. Экспериментальные данные для первой группы фенолов приведены в табл. 1.

Таблица 1

Характеристика продуктов окисления различных фенолов в щелочной среде

\begin{tabular}{|c|c|c|c|c|}
\hline \multirow[b]{2}{*}{ Фенол } & \multirow{2}{*}{$\begin{array}{c}\text { Растворимость } \\
\text { продуктов } \\
\text { окисления } \\
\text { в воде }\end{array}$} & \multirow{2}{*}{$\begin{array}{c}\text { Количество } \\
\text { подопытных } \\
\text { животных }\end{array}$} & \multicolumn{2}{|c|}{ Смертность } \\
\hline & & & количество & $\begin{array}{c}\% \text { от общего } \\
\text { количества }\end{array}$ \\
\hline
\end{tabular}

$\begin{array}{llrll}\text { a-Нафтол } & \text { нет } & 2 & 0 & 0 \\ \text { То же } & \text { да } & 5 & 0 & 0 \\ \text { Гидрохинон } & \text { да } & 13 & 0 & 0 \\ \text { Резорцин } & \text { да } & 10 & 0 & 0 \\ \text { Орцин } & \text { да } & 10 & 0 & 0 \\ \text { Смесь сланцевых фе- } & & & 0 & 0 \\ \quad \text { нолов (продукт А) } & \text { да } & 10 & 0 & 0\end{array}$

Эти данные показывают, что продукты окисления фенолов молекулярным кислородом в щелочной среде как растворимые, так и нерастворимые в воде, нельзя отнести к токсичным.

Результаты исследования реакционных смесей различного состава при окислительной деградации 5-метилрезорцина (орцина) в двух сериях 


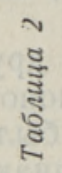

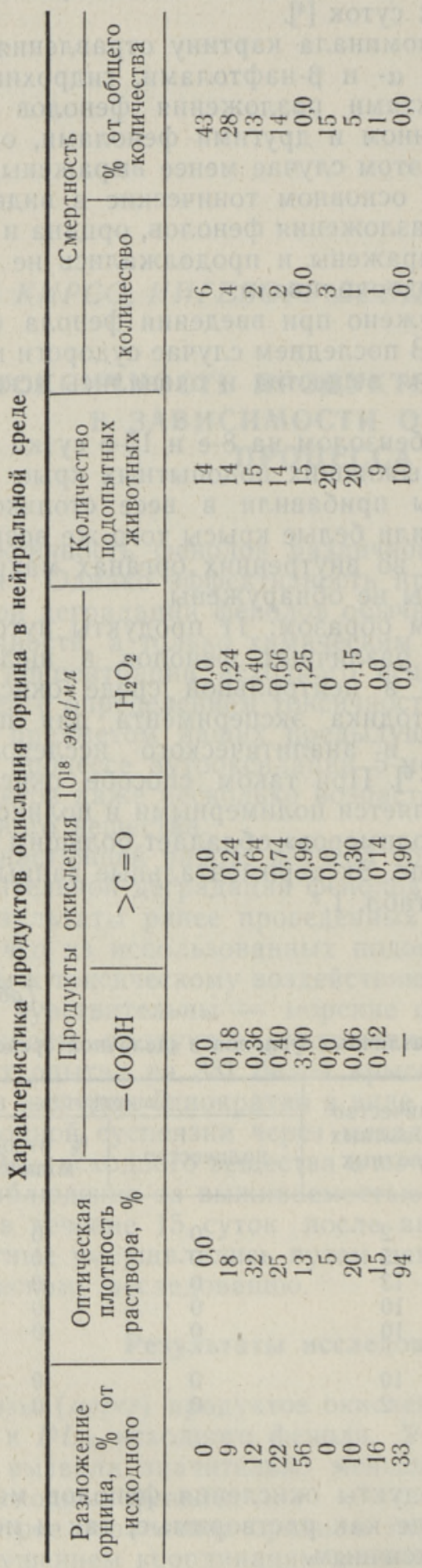

$\frac{\pi}{2}$

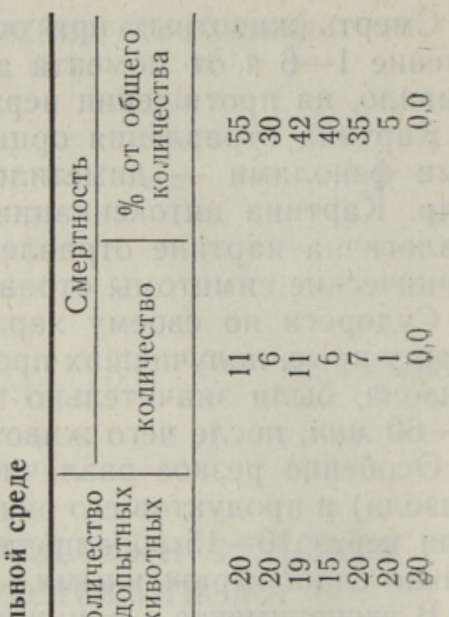

ลลำㄴํํำ

०.

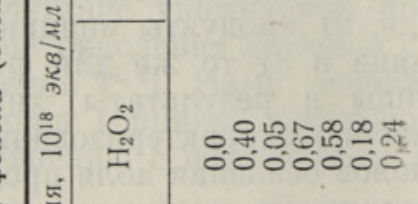

0000000

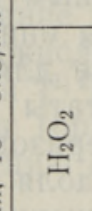

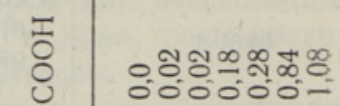

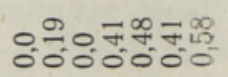

站

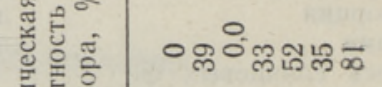

点志总

ํํㄹㅇํำ 
опытов даны в табл. 2. Деградация орцина происходит в процессе инициированного окисления его в $7 \%$-ном водном растворе. Продуктами окисления (см. табл. 2) являются главным образом малотоксичные соединения. Увеличение токсичности сопровождается в данном случае заметным повышением количества карбонильных групп.

Полученные аналогичным образом данные относительно продуктов активированного окисления оксибензола (фенола) сведены в табл. 3. Они свидетельствуют о том, что токсичность нейтрального водного раствора оксибензола снижается в процессе инициированного окисления.

Таким образом, можно считать установленным, что макромолекулярные продукты окисления фенолов разного строения в водощелочной среде не токсичны для белых крыс. С другой стороны, процесс окислительной деградации, стимулирующий образование сравнительно мелких осколков в продуктах окисления, также сопровождается снижением токсичности раствора. По-видимому, первичные продукты окисления, особенно с карбонильными функциями, обладают нанболее выраженными токсическими свойствами. Образование их наиболее вероятно при «медленном» окислении, т. е. при проведении процесса в условиях ограниченного или неравномерного доступа окислителя (кислорода) в систему.

Интересно также отметить, что для весьма существенного снижения токсичности раствора вовсе не требуется достижения $100 \%$-ной деградации исходного фенола. Так, по данным табл. 2, для обезвреживания раствора орцина достаточно достижения степени разложения $25-50 \%$ и по сведениям табл. 3 , смертность животных составляет лишь $5 \%$ при деградации фенола (оксибензола) всего до $25 \%$.

\section{Заключение}

В результате исследования токсичности продуктов окисления фенолов различной структуры определена взаимосвязь макромеханизма окисления с биологической активностью продуктов. Выявлено, что полимерные продукты окисления, равно как и мелкие осколки, не обладают выраженной токсичностью. Токсичность установлена для продуктов окисления с карбонильными функциями. Образование их наиболее вероятно при окислении фенолов в нейтральной среде и при ограниченном доступе кислорода.

\section{ЛИ Т Е Р А Т У Р А}

1. Велдре И. А., Кирсо У. Э., Тезисы докладов ХІІ научной сессии Института экспериментальной и клинической медицины Министерства здравоохранения ЭССР, Кохтла-Ярве, 1968 , с. 42.

2. Велдре И. А., К и рсо У. Э., В сб.: Вопросы гигиены труда и профпатологии в ЭССР, Таллин, 1970.

3. В елдре И. А., Гигиена и санитария, № 4, 14 (1969).

4. Велд ре И. А., К а рп уннн Б. И., М а ази к И. Х., В сб.: Вопросы гигиены труда и профпатологии в ЭССР, вып. 2, Таллин, 1970.

5. Ки р со У. Э., Г у бе р гр иц М. Я., К уй в К. А., Ж. прикл. химии, 41, 1257 (1968),

6. К и р со У. Э., Г уб ер г и ц М. Я., Ж. прикл. химии (1970, в печати).

\section{Ннститут химии \\ Академии наук Эстонской ССР}

Поступила в редакцию 29/IV 1970

Институт экспериментальной и клинической медицины Министерства здравоохранения Эстонской ССР 
UUVE KIRSO, INGEBORG VELDRE

\section{FENOOLIDE LAGUPRODUKTIDE TOKSILISUS SÕLTUVALT OKSODEERIMISPROTSESSI MEHHANISMIST}

Selgus, et erineva struktuuriga fenoolide oksüdeerimisproduktide toksilisus oleneb oksüdeerimisprotsessi makromehhanismist. Tehti kindlaks, et ei polümeerid ega sügavamad lōhmumisproduktid pole mürgised. Toksilised on karbonüülsete gruppidega primaarsed laguproduktid. Viimaste tekkimise tõenäosus on suuiem fenoolide oksüdeerimisel neutraalses keskkonnas ja piiratud hulga hapniku manulusel.

\section{UUVE KIRSO, INGEBORG VELDRE}

\section{THE OXIDATION MECHANISM OF PHENOLS AND THE TOXICAL PROPERTIES OF THEIR DEGRADATION PRODUCTS}

The relation between the chemical structure of phenols as well as the mechanism and extent of the toxicity of their various oxidation products has been studied.

The polymeric products of the oxidation of phenols and their minor degradation products do not possess any outspoken toxicity. However, the primary oxidation products, which perform carbonyl functions, were stated to be highly toxical. The probability of the formation of such compounds increases at the oxidation of phenols in a neutral medium, and with a restricted influx of oxygen. 